\title{
New adaptive hysteresis band width control for direct torque control of induction machine drives
}

\author{
Arkan A. Kadum \\ Department of Electronic Engineering, University of Kufa, Iraq
}

\begin{tabular}{l}
\hline \hline Article Info \\
\hline Article history: \\
Received Feb 6, 2019 \\
Revised Jul 8, 2019 \\
Accepted May 19, 2020 \\
\hline
\end{tabular}

\section{Keywords:}

Direct torque control

Estimators

Induction machine drive

Switching table

Torque ripple

\begin{abstract}
This paper presents a new adaptive hysteresis band control approach used in direct torque control (DTC) of the induction motor (IM) drives with the switching tables for the generation of PWM signals. Constant Hysteresis Direct torque control (CHB-DTC) method used the torque and stator flux errors to generate the stator voltage reference and frequency vectors for controlling the three-phase induction motor. The CHB-DTC gives better torque transient performance but it has large steady state ripples. To reduce torque and stator current ripples in CHB-DTC controlled induction motor drives a new adaptive hysteresis band control (AHB) approach is proposed, where the hysteresis band is adapted in real time with the stator flux and torque errors variation, instead of fixed bandwidth. Both classical CHB-DTC method and the proposed adaptive hysteresis band DTC (AHB-DTC) fed three induction motor have been simulated using Matlab/Simulink. The simulation results at different operating conditions over a wide speed range demonstrate the validity, effectiveness, and feasibility of the proposed scheme. The measurements showed that torque ripples were significantly decrease with the new AHB-DTC technique and better speed response in step up or down compared to the CHB-DTC.
\end{abstract}

This is an open access article under the CC BY-SA license.

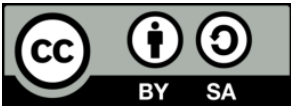

\section{Corresponding Author:}

Arkan A. Kadum

Department of Electrical Engineering,

University of Kufa

Kufa, Iraq

Email: arkanra@yahoo.com

\section{INTRODUCTION}

Many decades ago, three-phase Induction motors (IMs) were used limited constant speed applications due to speed change on induction machines have not only been difficult to realize but also require more expenses. Contrary, separately excited dc motors are simpler for the variable speed control applications because independent control of flux and torque can be brought about. But today, due to the advances in power semiconductor devices and microcontroller technology have made induction machines with variable speed drives to become popular $[1,2]$.

Active control systems in variable speed control applications are the system's essential mechanism for producing a result that is smooth and fairly insensitive to noise and disturbance. Consequently, many controller designs were used to control induction motors speed and torque via the vector control technique.

The methods of vector control can essentially be grouped in two headings Direct Torque Control (DTC) and Field Oriented Control (FOC). Field Oriented Control uses coordinate transformation to decouple the stator current and torque flux components. Consequently, the IM's performance is very analogous to that of the separately excited DC motor. The achievement of this method is complex and is well known to be 
extremely sensitive to variations in parameters because of the fee-forward mechanism of its control system [3]. Later in the eighties, a new control technique named DTC is introduced [4, 5]. In DTC it is possible to control directly the stator flux and the torque by selecting the appropriate inverter switching state. Because of some well-known benefits, including simple control structure, the DTC was a good alternative to FOC, no need for several motor parameters so the parameter independence changes, without the complex block of field-orientation and the inner current control loop [6,7], and provides a very fast and precise dynamic response. Since the inverter is operated directly by the algorithm, no modulation technique is needed. Besides these advantages, conventional DTC scheme still had some disadvantages such as variable switching losses in the inverter, flux drooping at low speed, sluggish, the response starts and changes in load and high torque and current ripples [8].

Recent, various techniques have been proposed to improve performances of the DTC, including the use of variable hysteresis bands [8-10], different observer models have been suggested [11-14], intelligent control methods and space vector modulation techniques [15-17] like fuzzy logic or neural networks [18, 19]. Several researchers have explored torque controllers that generate a constant torque switching frequency for their ability to improve the drive system speed control. [20-23], these techniques replace the conventional hysteresis torque controller with a constant switching frequency controller. Then, by comparing the triangular waveforms with the compensated torque error signal, an almost fixed switching frequency is obtained. [24-25].

In this paper, A new adaptive hysteresis band controller algorithm has been proposed to strengthen the DTC-controlled IM dynamic torque response. Here the hysteresis band is controlled in real time with the variation of stator flux and torque errors. Within the suggested algorithm, the correct voltage vector is used to precisely compensate for the errors within flux and torque. The CHB-DTC's torque and current ripples can be decreased significantly. To demonstrate the impact of the proposed method, traditional and proposed systems were simulated and findings analyzed in the Matlab/Simulink context. Simulation experiments have shown this approach reduces the DTC system's torque ripple.

\section{PRINCIPLE OF CLASSICAL DIRECT TORQUE CONTROL}

Direct torque control's fundamental concept is to control in real time both the torque and the magnitude of the flux within the related error bands by selecting the appropriate stator voltage vector. The block diagram of the classical DTC scheme for a VSI-fed Induction Motor is shown in Figure 1. It consists of torque and stator flux estimators, torque and flux hysteresis comparators, a switching table and a voltage source inverter (VSI).

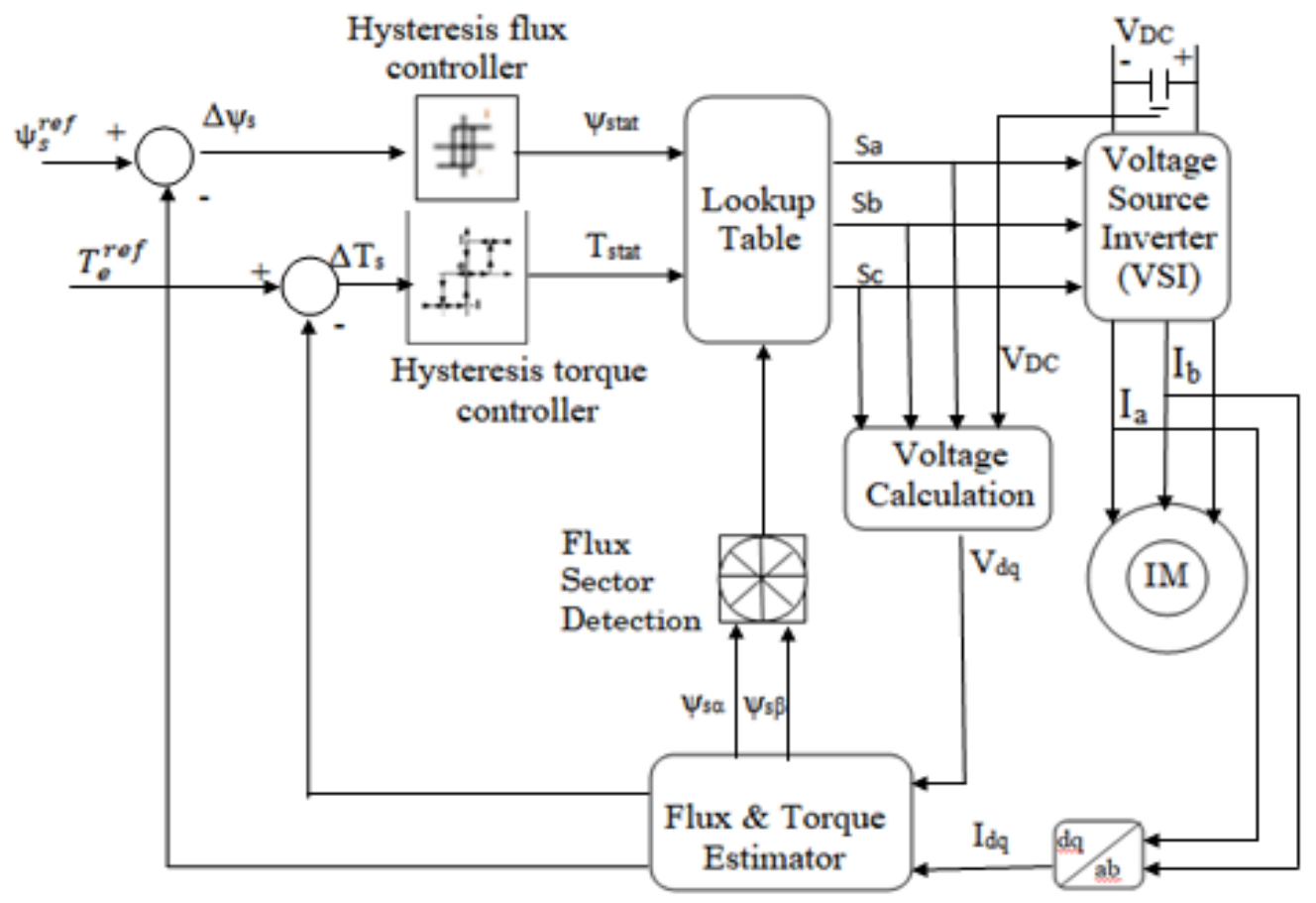

Figure1. Block diagram of DTC 


\subsection{Stator flux and torque estimation}

The stator flux vector of an induction motor is estimated by integrating the stator voltages and current vectors by [4]:

$$
\psi_{S}(t)=\int\left(v_{S}(t)-R_{S} i_{S}(t)\right) d t
$$

where: $\psi_{s}(\mathrm{t})$ is the stator flux vector; $\mathrm{v}_{\mathrm{s}}(\mathrm{t})$ and $\mathrm{i}_{\mathrm{s}}(\mathrm{t})$ are motor stator voltage vector and current vector respectively; $\mathrm{R}_{\mathrm{s}}$ is the motor stator resistance.

The estimation of stator flux using (1) can be split into the estimation of D and Q axis of stator flux, as follows.

$$
\begin{aligned}
& \psi_{S d}(t)=\int\left(v_{S d}(t)-R_{S} i_{S d}(t)\right) d t \\
& \psi_{S q}(t)=\int\left(v_{S q}(t)-R_{S} i_{S q}(t)\right) d t
\end{aligned}
$$

where the components of stator current and stator voltage in DQ coordinate can be simply calculated using the following equations,

$$
\begin{aligned}
& i_{s d}=i_{a} \\
& i_{s q}=\frac{\left(i_{a}-2 i_{b}\right)}{\sqrt{3}} \\
& v_{s d}=\frac{1}{3} V_{D C}\left(2 v_{a}-v_{b}-v_{c}\right) \\
& v_{s q}=1 / \sqrt{3} V_{D C}\left(v_{b}-v_{c}\right)
\end{aligned}
$$

where $i_{a}, i_{b}, v_{a}, v_{b}$, and $v_{c}$ are phase currents, and voltages respectively, and $V_{D C}$ is the input voltage of the inverter.

The (1) reveals that variations to the stator voltage vector directly affect the stator flux vector. On the contrary, the rotor and stator leakage inductances filter influence Vs over the rotor flux and are therefore not important over a short-term horizon. Since the stator flux can be rapidly modified while the rotor flux rotates more slowly, the angle between the two vectors can be regulated directly by Vs. The exact relationship between the stator and rotor fluxes shows that maintaining a constant amplitude of $\psi_{\mathrm{s}}$ would produce a constant flux $\psi_{\mathrm{r}}$.

The electromagnetic torque can be expressed according to the space vectors of the rotor flux and stator flux as follows:

$$
\begin{aligned}
T_{e} & =\frac{3}{2} P\left(\psi_{s} \times i_{s}\right)=\frac{3}{2} P\left[i_{q s} \psi_{d s}-i_{d s} \psi_{q s}\right] \\
& =\frac{3}{2} P \psi_{s} i_{s} \sin \left(\theta_{i s}-\theta_{\psi s}\right)=\frac{3}{2} P \psi_{s} i_{s} \sin (\delta)
\end{aligned}
$$

where: Te is the electromagnetic torque; $\mathrm{p}$ is the motor pole pair; $\psi_{\mathrm{s}}$ is the stator flux vector at the d-q coordinate, $\delta$ - angle between rotor flux vector and stator current vector.

The formula (9) can be transformed into the equation:

$$
T_{e}=\frac{3}{2} P \frac{L_{m}}{L_{r} L_{s}-L_{M}^{2}} \psi_{s} \psi_{r} \sin \left(\delta_{\psi}\right)
$$

where: $\delta_{\psi}$ - angle between rotor and stator flux vectors.

$$
\delta_{\psi}=\tan ^{-1}\left[\frac{\psi_{q s}}{\psi_{d s}}\right]
$$

where: Ls, Lr and Lm the motor stator, rotor inductance, and mutual inductance are respectively; and $\psi \mathrm{r}$ is rotor flux linkage amplitude.

It is noteworthy that the torque depends on the magnitude of the stator and rotor flux as well as the angle $\delta_{\psi}$. Figure 2 shows the vector diagram of current and flux vectors at the s-q coordinate. 


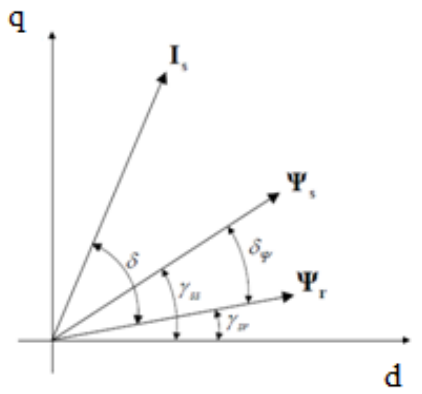

Figure 2 Vector diagram of vectors at $d-q$ coordinate

\subsection{Torque and flux hysteresis comparators}

As can be seen from Figure 1, there are two different loops related to the magnitudes of the stator flux modulus and torque. The reference values for the stator flux amplitude and the electromagnetic torque is compared with the estimated values. The flux controller is a comparator of two levels while the torque controller is a comparator of three levels, as it is shown in Figure 3.

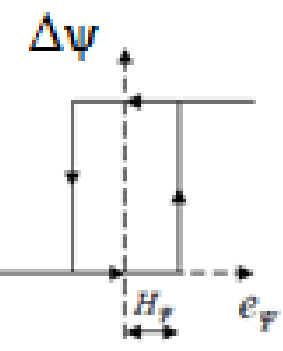

(a)

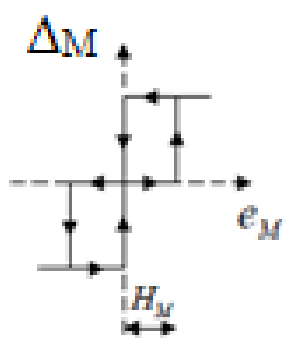

(b)

Figure 3. The hysteresis controllers (a) of two-level, (b) of three-level

The flux controller's digitized output signals are as described in equations (11) and (12)

$$
\begin{aligned}
& \psi_{\text {stat }}=1 \text { for } \psi_{s}<\psi_{s}^{\text {ref }}-H_{\psi} \\
& \psi_{\text {stat }}=-1 \text { for } \psi_{s}<\psi_{s}^{\text {ref }}+H_{\psi}
\end{aligned}
$$

And those of the torque controller are as in (13), (14) and (15)

$$
\begin{aligned}
& T_{\text {stat }}=1 \text { for } T_{e}<T_{e}^{\text {ref }}-H_{m} \\
& T_{\text {stat }}=0 \text { for } T_{e}=T_{e}^{\text {ref }} \\
& T_{\text {stat }}=-1 \text { for } T_{e}<T_{e}^{r e f}+H_{m}
\end{aligned}
$$

Where $2 \mathrm{H}_{\mathrm{m}}$ is the torque tolerance band and $2 \mathrm{H}_{\Psi}$ is the flux tolerance band.

\subsection{Switching table}

The classical DTC scheme is to select the appropriate voltage vector by means of lookup table voltage vector to achieve direct control of flux linkage and torque [6], making it limited within a certain error range. If the voltage vector is applied, the stator flux will increase the phase angle between the rotor flux and stator flux vectors, the resulting torque increases.

In the classical DTC method, the plane is divided for the six sectors. For the stator flux vector lying in sector 1 (Figure 4), the voltage vectors V1, V2, V6 can be chosen to increase flux vector magnitude. On the other side, to obtain a decrease flux vector magnitude can be by choosing V3, V4, V5. By applying one of 
the zero vectors $\mathrm{V} 0$ or $\mathrm{V} 7$ will reduce the electromagnetic torque, and stator flux vector $\psi \mathrm{s}$ is basically unchanged.

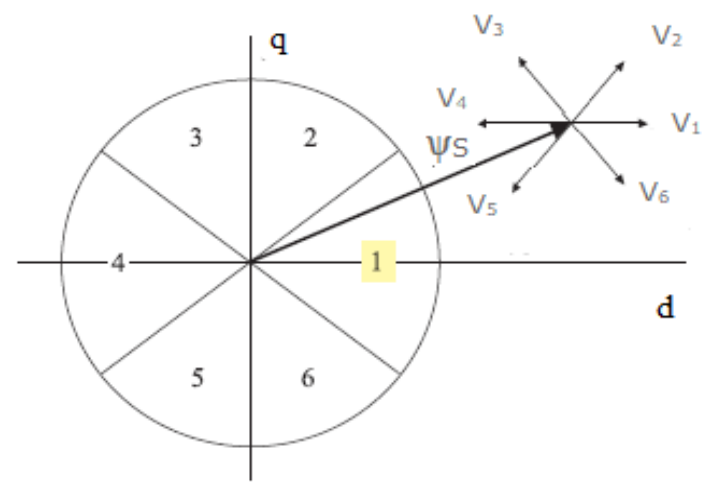

Figure 4. Selection of the appropriate voltage vectors for the stator flux vector in sector 1

For the torque control, the between stator and rotor flux $\delta_{\Psi}$ is used (9). Therefore, to increase motor torque the voltage vectors V2, V3, V4 can be selected and to decrease V1, V5, V6. The above considerations allow construction of the selection table as presented in Table 1.

Table 1. Switching table

\begin{tabular}{cccccccc}
\hline$\Delta \Psi$ & $\Delta \mathrm{M}$ & Sector 1 & Sector 2 & Sector 3 & Sector 4 & Sector 5 & Sector 6 \\
\hline \multirow{3}{*}{1} & 1 & $\mathrm{~V}_{2}$ & $\mathrm{~V}_{3}$ & $\mathrm{~V}_{4}$ & $\mathrm{~V}_{5}$ & $\mathrm{~V}_{6}$ & $\mathrm{~V}_{1}$ \\
& 0 & $\mathrm{~V}_{7}$ & $\mathrm{~V}_{0}$ & $\mathrm{~V}_{7}$ & $\mathrm{~V}_{0}$ & $\mathrm{~V}_{7}$ & $\mathrm{~V}_{0}$ \\
& -1 & $\mathrm{~V}_{6}$ & $\mathrm{~V}_{1}$ & $\mathrm{~V}_{2}$ & $\mathrm{~V}_{3}$ & $\mathrm{~V}_{4}$ & $\mathrm{~V}_{5}$ \\
0 & 1 & $\mathrm{~V}_{3}$ & $\mathrm{~V}_{4}$ & $\mathrm{~V}_{5}$ & $\mathrm{~V}_{6}$ & $\mathrm{~V}_{1}$ & $\mathrm{~V}_{2}$ \\
& 0 & $\mathrm{~V}_{0}$ & $\mathrm{~V}_{7}$ & $\mathrm{~V}_{0}$ & $\mathrm{~V}_{7}$ & $\mathrm{~V}_{0}$ & $\mathrm{~V}_{7}$ \\
& -1 & $\mathrm{~V}_{5}$ & $\mathrm{~V}_{6}$ & $\mathrm{~V}_{1}$ & $\mathrm{~V}_{2}$ & $\mathrm{~V}_{3}$ & $\mathrm{~V}_{4}$ \\
\hline
\end{tabular}

\section{ADAPTIVE HYSTERESIS BAND ALGORITHM}

The adaptive hysteresis algorithm, as shown below in Figure 5, operates by incrementing or decrementing the hysteresis width by comparing the (error $\psi$ ) with that of the previous one (error $\psi$ old.). The algorithm starting by measures the instant flux error error $\psi$ and the previous error (error $\psi$ old) to calculate the rate of change and then compare it with zero value. If the error $\psi$ )/error $\psi$ old $\geq 0$ the hysteresis width increases by $\delta \mathrm{H} \psi \mathrm{M}$, so the voltage vector stays in the same direction; otherwised, the hysteresis width is decrease by $\delta \mathrm{H} \psi \mathrm{m}$. In the next cycle the algorithm continues in the same way, and the hysteresis width is kept on changing in the same manner until it reaches its max value or min value.

The variation is the bandwidth of the hysteresis controller results in the varying switching frequency of the inverter. When the hysteresis width $\Delta \mathrm{H}$ is the minimum the switching frequency is maximum. This is mainly true in study state conditions contrary under quick torque response in the transient region the hysteresis width will be changed or it will be max.

The DTC method has two different hysteresis controllers, flux and electromagnetic torque. The same idea of the algorithm applied to both controllers. The hysteresis bandwidth is constructed to be dynamic in this way, and the control algorithm attempts to reduce the error at each step. In other words, this algorithm correlates the error of torque and flux with each other. 


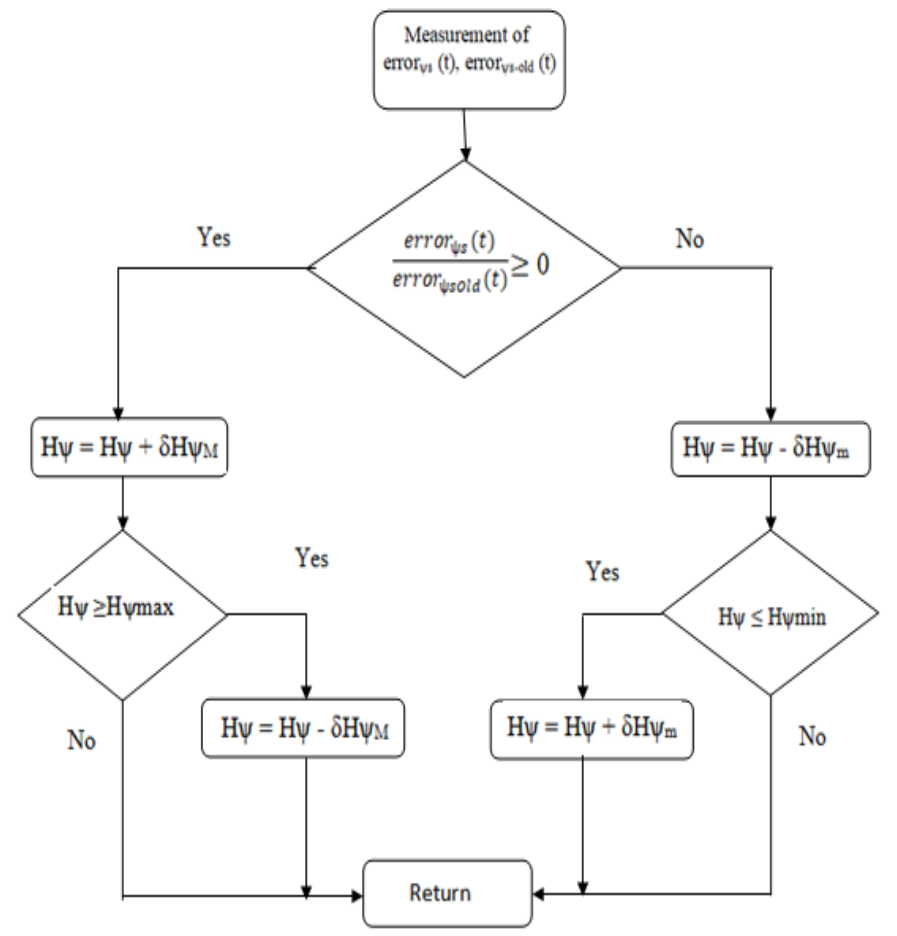

Figure 5. Flow chart of the proposed algorithm

\section{SIMULATION RESULTS OF THE PROPOSED SYSTEM}

In order to verify the AHB -DTC scheme, simulations are performed in this section. The threephase induction motor parameters for use in Matlab/Simulink model are shown as in table 3.

The simulation has been performed for stator flux and torque hysteresis band amplitude for DTC are $0.005 \mathrm{~Wb}$ and $.05 \mathrm{~Wb}$ respectively where for ADDTC are as shown in table 2.

Table2. Parameter of controller

\begin{tabular}{|c|c|c|c|}
\hline Flux Parameter & Amplitude (wb) & Torque Parameter & Amplitude (wb) \\
\hline Max flux hysteresis width of $\mathrm{H} \psi_{\max }$ & .005 & Max torque hysteresis width of $\mathrm{H}_{\mathrm{Tmax}}$ & .05 \\
\hline $\begin{array}{l}\text { A small change of hysteresis width } \\
\text { to adjust the max value } \delta \mathrm{H} \psi_{\mathrm{M}}\end{array}$ & .001 & $\begin{array}{l}\text { A small change of hysteresis width } \\
\text { to adjust the max value } \delta \mathrm{H}_{\mathrm{TM}}\end{array}$ & .001 \\
\hline $\begin{array}{l}\text { A small change of hysteresis width } \\
\text { to adjust the min value } \delta \mathrm{H} \psi \mathrm{m}\end{array}$ & 0001 & $\begin{array}{l}\text { A small change of hysteresis width } \\
\text { to adjust the min value } \delta \mathrm{H}_{\mathrm{Tm}}\end{array}$ & .0001 \\
\hline Min flux hysteresis width of $\mathrm{H} \psi_{\min }$ & .00001 & Min torque hysteresis width of $\mathrm{H}_{\mathrm{T} \text { min }}$ & .00001 \\
\hline
\end{tabular}

Table3. Parameter of IM

\begin{tabular}{ll}
\hline Power Rating & $3 \mathrm{KW}$ \\
\hline Nominal Voltage Vs & $380 \mathrm{~V}$ \\
Nominal Speed & $1440 \mathrm{rpm}$, \\
Resistance of Stator Rs & $1.850 \Omega$ \\
Resistance of Rotor Rr & $1.840 \Omega$ \\
Self inductance of Stator Ls & $0.17 \mathrm{H}$ \\
Self inductance of Rotor Lr & $0.170 \mathrm{H}$ \\
Mutual inductance Lm & $0.160 \mathrm{H}$ \\
No of pole pairs p & 2 \\
Stator flux linkage $\psi \mathrm{s}$ & $0.8(\mathrm{~Wb})$ \\
squirrel-cage IM & \\
\hline
\end{tabular}

In order to evaluate the performance of the DTC-based ADHB, it takes into account three operating conditions: the variable speed with no load, full speed with variable load and variable speed with variable load. 


\subsection{Speed performance}

The simulation waveforms of the Speed, stator flux, and stator phase "a" current at different speed regions under no load are shown in Figure 6 for both Classical direct torque control and adaptive hysteresis direct torque control.

Initially, the reference speed is set to rated speed $186.4 \mathrm{rad} / \mathrm{s}(1500 \mathrm{rpm})$ and then stepped down to very low $8 \mathrm{rad} / \mathrm{s}$. The second step the reference speed is increased to $55 \mathrm{rad} / \mathrm{s}$. For both schemes, the estimated and measured stator flux waveforms are shown in Figure 6.

As can be seen from the figure, steady-state error for AHB-DTC is $0.08 \%$ where for Classical-DTC is $0.14 \%$. By using adaptive hysteresis direct torque control, it shown that the flux regulation works fine even the speed is stepped up or down. The estimated flux follows exactly the measured flux.

Plotting of the direct stator flux $\psi d$ against the quadrature stator flux $\psi q$ is shown in figure 7 by using variable speed. Figure 7(b) demonstrates there is an enhancement in IM drive stator flux trajectory, compared with conventional DTC; the AHB has much lesser torque ripple. It can be seen from Figs. 6 and 7 , the proposed AHB can estimate the stator flux better and almost circular flux trajectory with the same amplitudes in both $\mathrm{d}$ and $\mathrm{q}$ axes assures correct offset compensation.

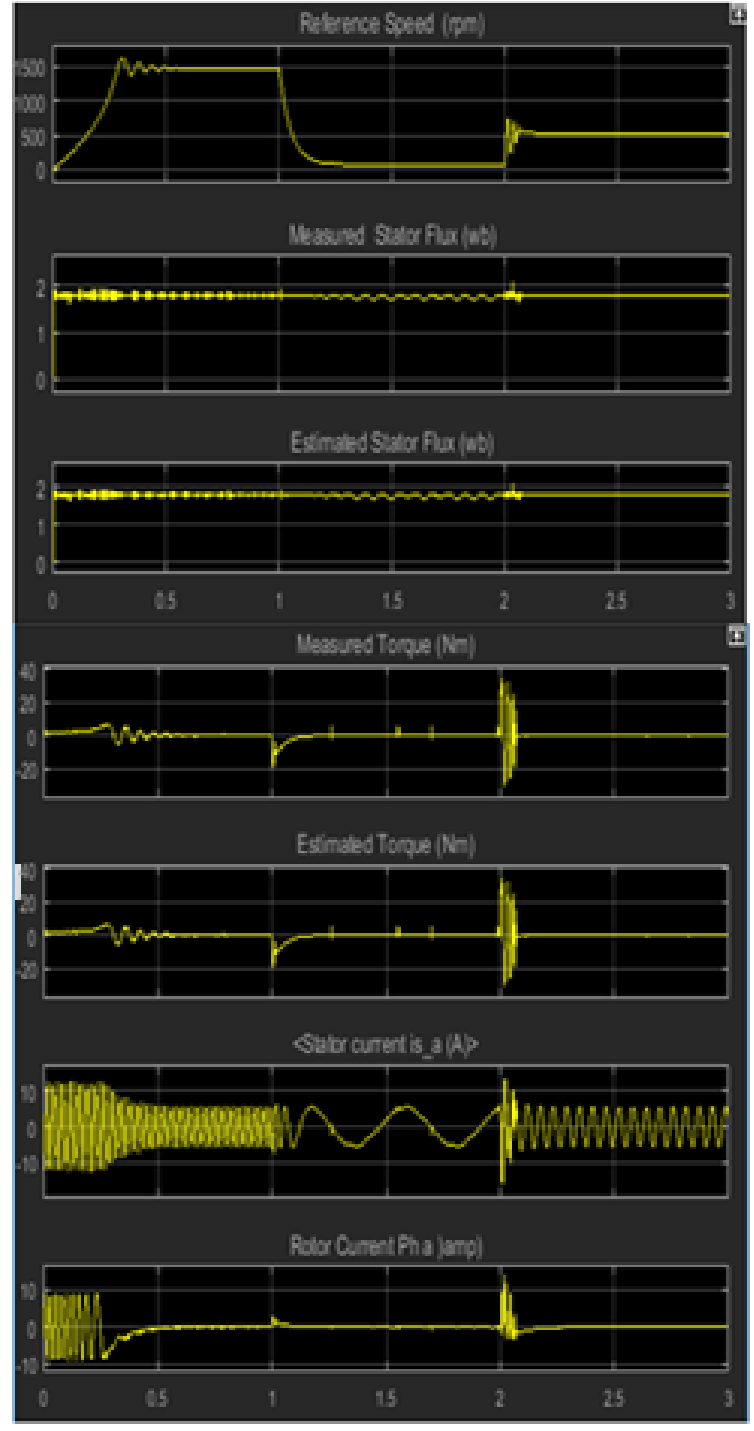

(a)

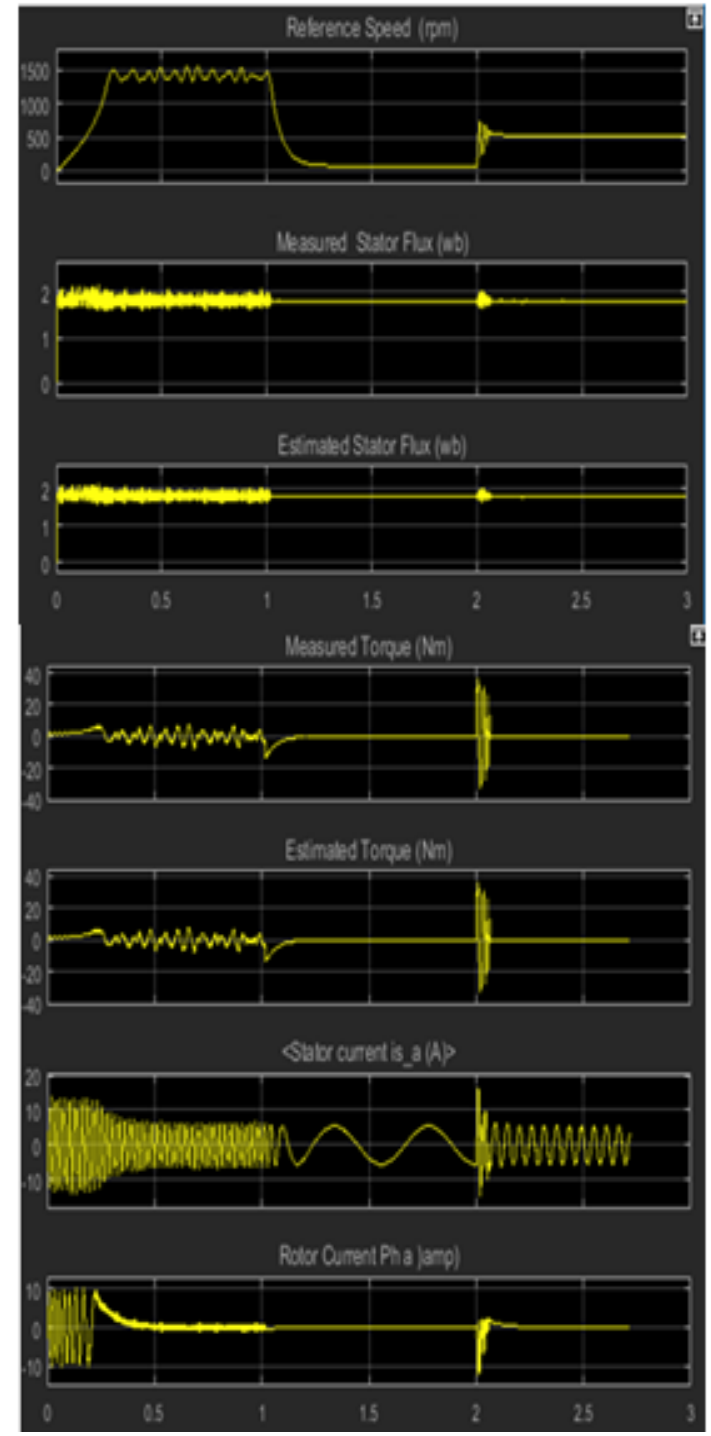

(b)

Figure 6. Motor speed response under different reference speed (a) Classical-DTC (b) AHB-DTC 


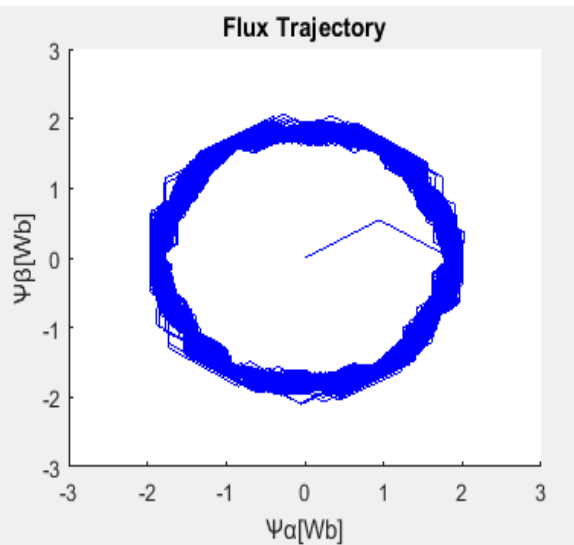

(a)

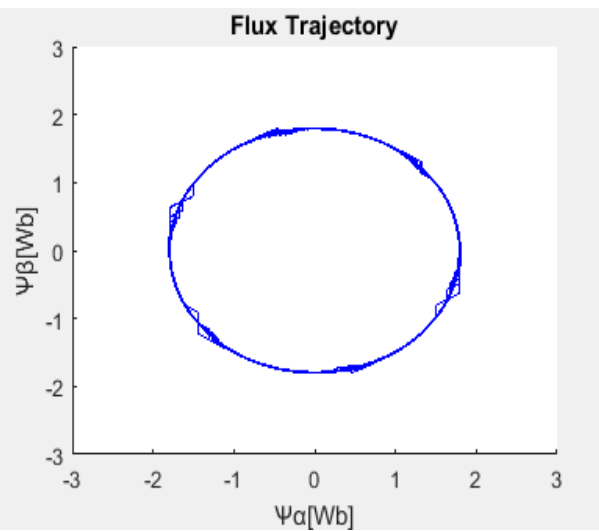

(b)

Figure 7. Stator flux trajectory curve under no load speed (a) Classical-DTC (b) AHB-DTC

\subsection{Load performance}

The speed response under no-load, full load, 50\% full load, and 75\% full load condition are shown in Figure 8(a) of classical-DTC and proposed DTC-SVM are shown Figure 8(b). At startup, the system is unloaded, and the system run at rated speed. The reference load is set to full load $(16 \mathrm{Nm})$ after $1 \mathrm{sec}$, then stepped down after another sec to $50 \%$ after one sec, the reference load is stepped up to $75 \%$ of full load. The waveforms of the measured and reference torque, and stator fluxes, for both schemes, are shown in Figure 8.

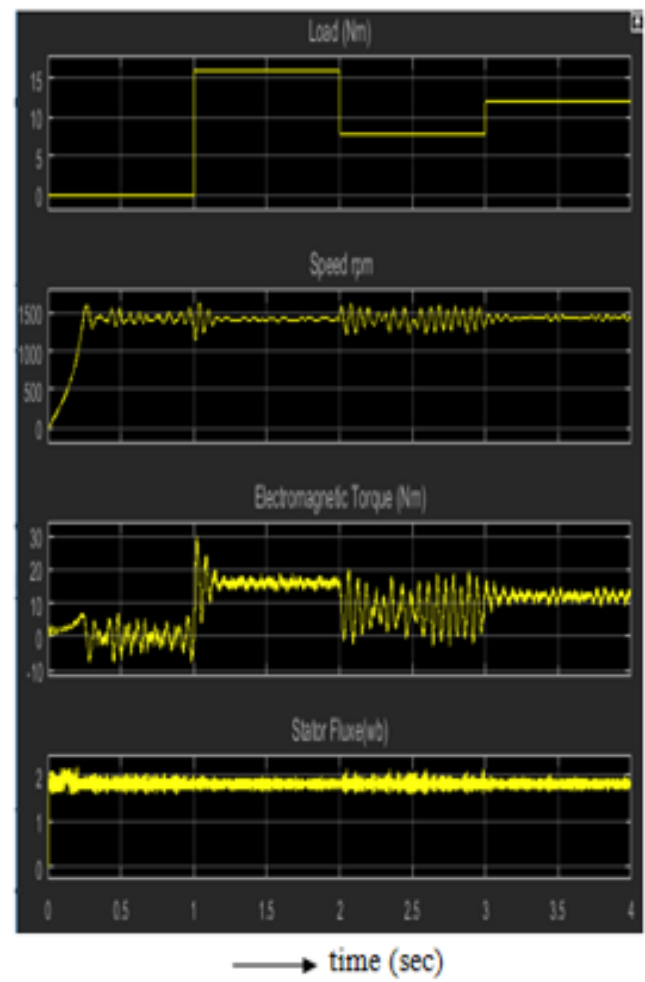

(a)

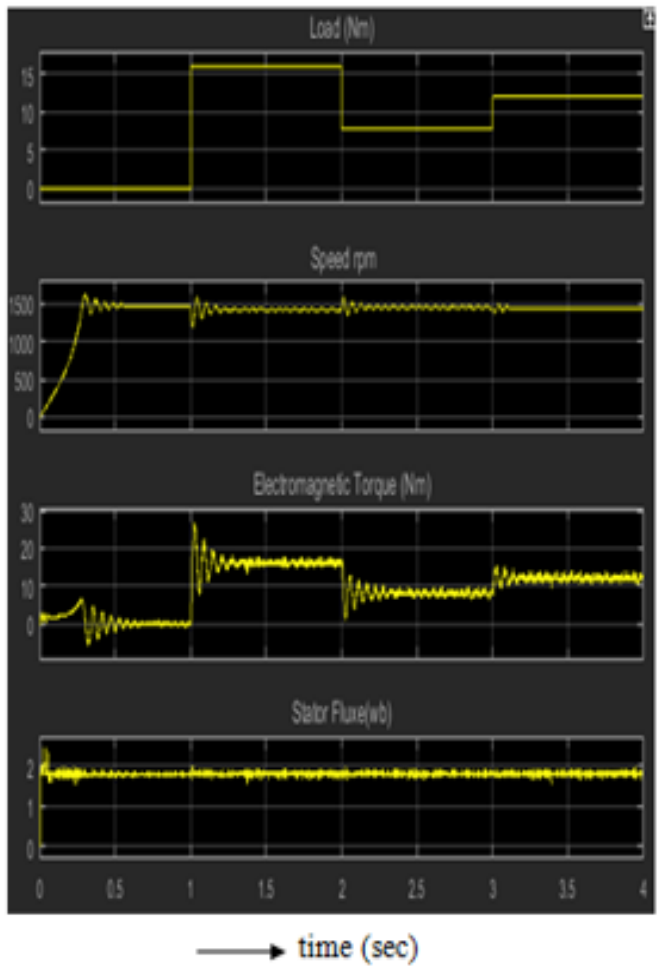

(b)

Figure 8. Motor response under rated speed and different load (a) Classical-DTC (b) AHB-DTC

In the case of AHB-DTC, the speed goes down from 1477 to $1453 \mathrm{rpm}$ when the system is fully loaded, where the speed is stepped down from 1447 to $1398 \mathrm{rpm}$ in case of classical DTC. 


\subsection{Speed and load Performance}

A response for different speed under no-load, full load, $25 \%$ full load, and $75 \%$ full load condition are shown in Figure 9(a) of classical-DTC and proposed DTC-SVM are shown Figure 9(b).

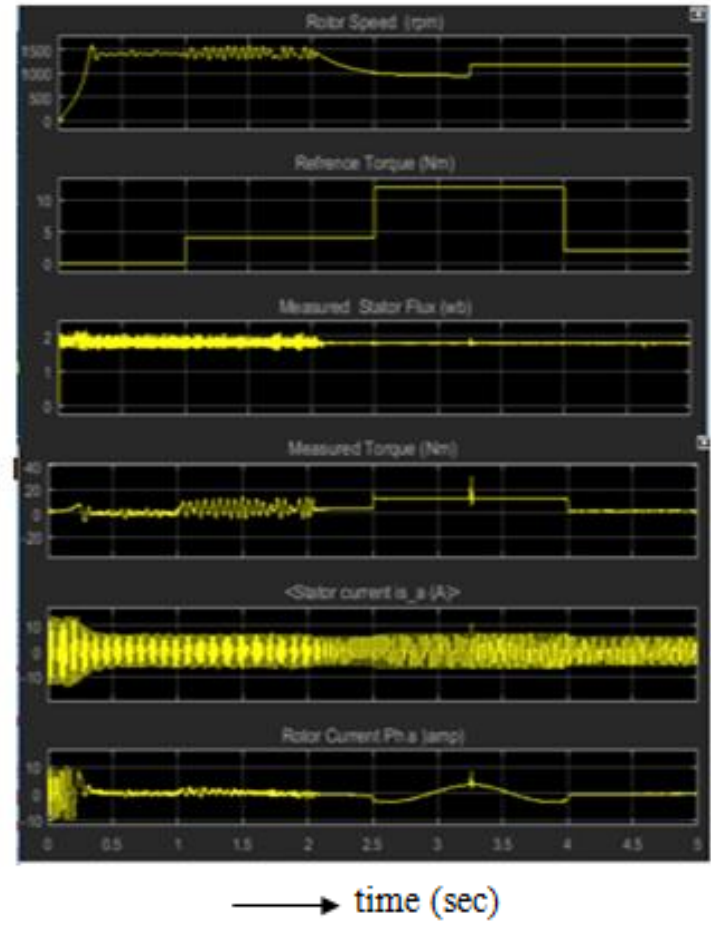

(a)

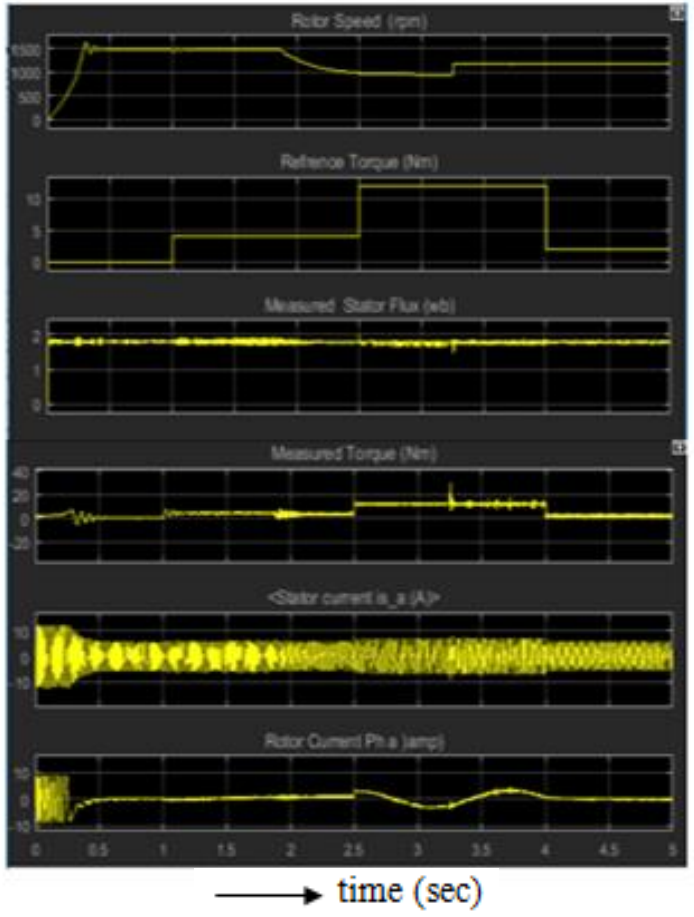

(b)

Figure 9. Motor response under different speed and load (a) Classical-DTC (b) AHB-DT

The speed set up to rate, $50 \%$ of rated, and then to $75 \%$ of the rated speed. Deferent value of torque is applied at a different time. In Figure 9 (b), the response of speed with the short time which is needed by the mechanical load to arrive rated value. These findings indicate a good and fast response to the proposed drive system.

Compared with conventional DTC, the AHB-DTC has much smaller torque ripple. From Figures 8 and 9 , it can be seen that the adaptive hysteresis can estimate the stator flux well and truly.

\section{CONCLUSIONS}

To reduce torque and stator current ripples in CHB-DTC controlled induction motor drives a new adaptive hysteresis band control strategy has been presented. In this approach, the tow and three levels hysteresis controller bandwidth have been adapted in real time based on the variation of present and previous stator flux and torque errors. Both classical DTC method and the adaptive hysteresis band DTC fed three induction motor drive schemes have been simulated using Matlab/Simulink software. The simulations results of the speed and the torque responses obtained and compared with CHB-DTC method at different operating conditions over a wide speed range and torque. The results obtained show that the presented DTC method proposed has been decrease the speed steady state error at full speed in no load or full load form 0.14 to 0.08 $\%$ and that improve the driver performance. The results demonstrate the validity of the proposed control. The comparisons showed that torque ripples were substantially reduced compared to the classical DTC with the proposed AHB-DTC system, and better speed response in step up or down.

\section{REFERENCES}

[1] Bose Bimal K., "An Adaptive Hysteresis-Band Current Control Technique of a Voltage-Fed PWM Inverter for Machine Drive System”, IEEE Trans. Ind. Electron., vol 37, pp. 402-408, Oct. 1990 
[2] P. Santhi Kumar and K. Nagalinka, "Flux vector control with space vector modulation for PWM inverter fed induction motor drive," International Journal of application or innovation in Engineering and Management (IJAIEM), vol.2, 2013.

[3] Krishnan, R., "Electric Motor Drives- Modeling, Analysis, and Control”, Prentice-Hall of India, 2002.

[4] Takahashi, L., and Noguchi, T., "A new quick response and high efficiency control strategy of an induction motor", IEEE Trans. on Industry Applications, 1A-22, pp. 820-827, 1986.

[5] Takahashi, I., and Ohmori, Y., "High-performance direct torque control of an induction motor", IEEE Trans. Ind. Applications, Vol. 25, No. 2, pp. 257-264, 1989.

[6] Rakesh Parekh, "AC Induction Motor Fundamentals", Microchip Technology Inc, AN887, DS00887A, pp 1-24, 2003.

[7] Blaschke, F. "The Principle of Field Orientation Applied to The New Transvector Closed-Loop Control System for Rotating Field Machines”, Siemens-Rev., Vol. 39, 217-220, 1972.

[8] J.K. Kang, D.W. Chung, S.K. Sul, "Direct Torque Control of Induction Machine with Variable Amplitude Control of Flux and Torque Hysteresis Bands”, IEEE/ IEMD Intn. Conf. pp. 640-642, 1999.

[9] Ren Y, Zhu Z, "Enhancement of steady-state performance in direct torque controlled dual-three phase permanent magnet synchronous machine drives with modified switching table." IEEE Transactions on Industrial Electronics, Vol. 62, No. 6, pp 3338-3350, 2015

[10] Hafeez M, Uddin M, Rahim N A. Ping H W. "Self-tuned NFC and adaptive torque hysteresis-based DTC scheme for IM drive". IEEE Transactions on Industry Applications, Vol. 50, No: 2: pp.1410-1420, 2014.

[11] Z. Tan. \& Y. Li. \& Y. Zeng, "A three-level speed sensorless DTC drive of induction motor based on a full-order flux observer", Power System Technology, Proceedings. PowerCon International Conference, vol. 2, pp. 1054$1058,2002$.

[12] G. Yav. \& L. Weiguo, "A new method research of fuzzy DTC based on full-order state observer forstator flux linkage", Computer Science and Automation Engineering (CSAE), 2011 IEEE International Conference, vol. 2, pp.104-108, 2011.

[13] Saghafinia A, Ping H, Uddin M, Gaeid K. "Adaptive fuzzy slidingmode control into chattering-free IM drive," IEEE Transactions on Industry Applications, Volume: 51, Issue, 1, Jan.-Feb. 2015; pp: 692 - 701

[14] Barambones O, Alkorta P. "Position control of the induction motor using an adaptive sliding-mode controller and observers." IEEE Transactions on Industrial Electronics, Volume: 61, Issue: 12, Dec. 2014; pp: 6556 - 6565

[15] L. Tan and M. F. Rahman, "A new direct torque control strategy for flux and torque ripple reduction for inductionmotors drive by using space vector modulation," in Proc. 32nd Annu. PESC, 2001, vol. 3, pp. 1440-1445.

[16] Zhifeng Zhang; Renyuan Tang, Baodong Bai, Dexin Xie, "Novel Direct Torque Control Based on Space Vector Modulation With Adaptive Stator Flux Observer for Induction Motors"; IEEE Transactions on Magnetics, Vol. 46, No. 8; pp 3133-3136, 2010.

[17] Priyanka P. Bawankule; S.S. Gokhale; "Direct Torque control of induction motors based on space vector modulation"; 2016 International Conference on Energy Efficient Technologies for Sustainability (ICEETS), INSPEC Accession Number: 16374331

[18] K. Suman; K. Suneeta; M. Sasikala; "Direct Torque Controlled induction motor drive with space vector modulation fed with three-level inverter," IEEE International Conference on Power Electronics, Drives and Energy Systems (PEDES); 16-19 Dec. 2012; INSPEC Accession Number: 13400126

[19] S. Mir and M. E. Elbuluk, "Precision torque control in inverter-fed induction machines using fuzzy logic," in Proc. IEEE-IAS Annu. Meeting, 1995, pp. 396-401.

[20] S. Benaicha. \& F. Zidani. \& R.-N. Said. \& M.-S.-N. Said, "Direct torque with fuzzy logic torque ripple reductionbased stator flux vector control", Computer and Electrical Engineering, (ICCEE '09), vol.2, pp. 128-133, 2009.

[21] N. Sadati. \& S. Kaboli. \& H. Adeli. \& E. Hajipour. \& M. Ferdowsi, "Online optimal neurofuzzy flux controller for dtc based induction motor drives", Applied Power Electronics Conference and Exposition (APEC 2009), pp.210-215, 2009.

[22] N. R. N. Idris and A. H. M. Yatim, "Reduced torque ripple and constant torque switching frequency strategy for Direct Torque Control of induction machine," in Proc. 15th IEEE-APEC, New Orleans, LA, pp. 154-161, 2000.

[23] N. R. N. Idris and A. H. M. Yatim, "Direct torque control of induction machines with constant switching frequency and reduced torque ripple," IEEE Trans. Ind. Electron., vol. 51, no. 4, pp. 758-767, Aug. 2004.

[24] Zaafouri A, Regaya C, Azza H, Châari A. "DSP-based adaptive back stepping using the tracking errors for highperformance sensorless speed control of induction motor drive." ISA Transactions, Vol. 60, pp 333-347, 2016.

[25] C. L. Toh, N. R. N. Idris, and A. H.M. Yatim, "Constant and high switching frequency torque controller for DTC drives,” IEEE Power Electron. Lett., vol. 3, no. 2, pp. 76-80, Jun. 2005. 